\title{
Maximizing the impacts of academic research
}

\section{A Book review of Dunleavy, P. and Tinkler, J. (2021) Maximizing the impacts of academic research. London: Red Globe Press.}

\author{
Samantha Ahern \\ University College London, UK
}

Keywords: Academic writing; research; knowledge exchange; citation; impact.

\section{Overview}

For those pursuing a career in academia, research output and its impact plays a key role in obtaining academic positions and research funding. The tagline of this book is 'How to grow the recognition, influence, practical application and public understanding of science and scholarship'. This is a very useful reference text for those who are undertaking doctoral studies or for early career researchers. The content of the book is organised into three parts: part one: academic impacts, part two: academic and external impacts, and part three: external impacts.

Part one is the most useful in supporting learning development as it provides a range of useful figures that will help all students develop their information literacy and writing skills. The latter sections would better support doctoral students and early career researchers in designing and developing research dissemination plans and directions in which to take their research. The book closes with an afterword that reiterates the importance of knowledge sharing for wider societal benefit.

\section{Content and Structure}

The opening chapters provide an overview of how citations work, citation tracking mechanisms, and the different impact factors, including alt metrics. These themes are discussed in relation to different discipline areas and the factors that can influence 
academics' and researchers' total citations, both positive and negative. Developing an understanding of these metrics is an important tool in helping students develop their information literacy, and will enable them to undertake effective reviews of literature. In addition, it will support early career researchers (ECRs) in understanding their own metrics and the nature of research outputs in their discipline area. The remaining chapters in this section are more practical in nature. Chapters three and four focus on journal articles, whereas chapter five's focus is on books and book chapters. Particularly useful in chapter three, is Figure 3.3, 'comparing journals when choosing where to publish'. Chapter four's focus is on how to craft better articles, including guidance on article structure and selecting a title. Figures 4.4 and 4.5 distil the key content and provide helpful prompts. Unlike other texts such as Graff and Birkenstein's 'They Say/l Say' (2010) which focuses on the development of arguments within academic writing, the focus is on the structure and discoverability of the writing. This is a different, but useful, resource for helping students develop their academic writing skills. However, as noted by Elton (2010), authors should be mindful of not being constrained by tacit knowledge becoming overt. Chapter five discusses the potential benefits and considerations of various book authorship and contribution scenarios in regard to a range of academic disciplines. In addition to guidance on selecting a title and authorship, there are overviews of the peer-review process for authored books and chapters in edited books, providing a useful description of the process for those who have not previously authored or contributed to edited books.

Part two takes a longer term and broader view of research activity and its impacts. Chapter six discuses non-traditional resource outputs and research portfolios, chapter seven focuses on the affordances of digital scholarship, and chapter eight dives into improving impact at department and institutional level. Chapter six is particularly useful for highlighting the types of activities academic engage in and how different outputs are cited and evidenced in the REF. The content of this chapter will help ECRs plan and manage a range of outputs across projects and will help them facilitate recognition of these outputs. Chapter seven introduces and discusses core concepts of digital scholarship for both facilitation and dissemination of research activity including new publication and review models such as those used by PLOS One. Chapters seven and eight overlap with their discussion of blogs: Figure 7.4 is a deep dive into the characteristics of different blog types; chapter eight gets more into the nature of different communication models and the nature of the communications materials created. It goes beyond the individual researcher, and looks at departmental and institutional practices. 
Part three focuses solely on external impacts. There is some overlap in the content of this section with that of chapter eight. Chapter nine dives a bit more into what is meant by impact, how it can be recognised, and how research interfaces with wider society. Chapter ten, 'working with other organizations', is a detailed overview of the key considerations for individual researchers, research teams, and institutions when working with external organizations. The figures in this chapter provide an overview of the key information. The closing chapter in this section, chapter eleven, returns to the topic on impact, but through the lens of public engagement. It discusses knowledge exchange in the public sphere and how to present the knowledge in an accessible and engaging way to the wider public. The figures for this chapter provide in-depth guides and prompts for public engagement.

\section{Summary}

This is an incredibly in-depth book that discusses all they key areas related to the dissemination of academic research, both within academia and beyond. However, at times it feels as though it drifts into the academese which it warns authors against in the opening chapters. The figures are incredibly useful resources and provide a good way of dipping into the key content of each of the chapters, without having to engage with the full text. However, in some sections the discussion and examples are predominantly Science, Technology, Engineering, Maths, and Medical sciences (STEMM) focused, with limited discussion relating to the humanities, arts, or social sciences. The latter chapters of the book are more slanted towards principle investigators and more senior researchers, making it a useful resource throughout a researcher's career.

In summary, this is a useful reference book with sections appealing to researchers at different stages of their careers. My recommendation would be to dip into the key areas of interest, as and when required.

\section{References}

Elton, L. (2010) 'Academic writing and tacit knowledge', Teaching in Higher Education, 15(2), pp. 151-160. 
Graff, G. and Birkenstein, C. (2010) 'They say, I say': the moves that matter in academic writing. $2^{\text {nd }}$ ed. New York: Norton.

\section{Author Details}

Samantha Ahern is a Faculty Learning Technology Lead at UCL. In addition to her main role, her interests include open education, equitable and inclusive education, and EdTech ethics. Her research focus is learning analytics and wellbeing. 